\title{
Pengaruh Teknik Pembelajaran Dan Kecerdasan Linguistik Terhadap Keterampilan Menulis Teks Recount Bahasa Inggris
}

\author{
${ }^{1}$ Oktariyani, ${ }^{2}$ Layni Asra \\ ${ }^{1}$ Universitas Nahdlatul Ulama Lampung \\ email : oktariyani.yani@yahoo.co.id \\ ${ }^{2}$ SMP Negeri 1 Sumber Jaya Lampung Barat \\ email : lainiasra@gmail.com
}

\author{
Cara Sitasi: \\ Oktariyani, \& Asra, L. (2018). Pengaruh Teknik Pembelajaran Dan Kecerdasan Linguistik Terhadap \\ Keterampilan Menulis Teks Recount Bahasa Inggris. Wanastra2, 10(2), 65-72.
}

\begin{abstract}
This research aimed at finding out the effect of learning technique and linguistic intelligence towards recount text writing skill in SMPN 1 Way Tenong West Lampung. The research used a $2 x 2$ factorial design. The sample was 30 students selected from the students of SMPN 2 Way Tenong West Lampung through multistage random sampling. There were two chosen groups as experimental. The first group taught by using Cooperative Integrated reading Composition (CIRC) learning technique and second group taught by Student Team Achievement Division (STAD) learning technique. The results of this research showed that (1) there is a difference score of the recount text writing skills English language learning among groups of students using learning techniques (CIRC) and a group of students who are learning using learning techniques (STAD) (the score of $F=0.99>F$ 0.258), (2) there is a positive interaction between teaching technique and linguistic intelligence (high and low) on the results of recount text writing skills in English $(F$ value $=25.50>F=2.95$ for $\alpha=0.05$ and $\alpha=0.01)$, (3) the students who have high linguistic intelligence, there are differences in the score of the recount text writing skills English language students better use learning techniques (STAD) than the group of students with teaching techniques (CIRC), (Qhit $=7.45>$ Qtab $=3.15$ at level $\alpha=0.05$ and $\alpha=0.01)$. (4) the students who have low linguistic intelligence linguistic, there is a difference in the score of the recount text writing skills English language students better used teaching techniques (CIRC) than the group of students with teaching techniques $(S T A D),(Q h i t=10.18>Q$ tab $=3.15$ at level $\alpha=0.05$ and $\alpha=0.01)$.
\end{abstract}

\section{Key words: Recount Text Writing Skill, Learning Technique: CIRC And STAD, Intelligence Linguistic}

\section{PENDAHULUAN}

Semua keterampilan berbahasa yang mencakup keterampilan menyimak, berbicara, membaca dan menulis keempatnya sama-sama memiliki peranan yang penting dan strategis. Secara alami perkembangan keterampilan berbahasa seseorang berawal dari keterampilan menyimak, kemudian diikuti keterampilan berbicara. Hal ini bisa kita lihat dalam perkembangan dan pemerolehan bahasa seorang anak. Setelah fase itu, seorang anak dapat berlatih keterampilan membaca, yang kemudian diikuti keterampilan menulis. Hanya saja taraf keterampilam berbahasa lebih lanjut tidak sebatas perkembangan alami. Taraf keterampilan berbahasa tentu saja sesuai dengan taraf perkembangan psikologis seseorang. Hal ini bisa kita lihat dalam perkembangan kompetensi yang dimiliki oleh pembelajar, mulai sekolah dasar hingga ke sekolah menengah, bahkan hingga perguruan tinggi.

Sementara dalam keterampilan menulis atau mengarang merupakan kegiatan yang kompleks.
Kompleksitas menulis terletak pada tuntutan kemampuan untuk menata dan mengorganisasikan ide secara runtut dan logis, serta menyajikannya dalam ragam bahasa tulis dan kaidah penulisan lainnya. Akan tetapi, di balik kerumitannya, menulis menjanjikan manfaat yang begitu besar dalam membantu pengembangan daya inisiatif dan kreativitas, kepercayaan diri dan keberanian, serta kebiasaan dan kemampuan dalam menemukan, mengumpulkan, mengolah, dan menata informasi.

Menulis menurut Mark Connelly (2013: 2) adalah proses sebagaimana untuk menghasilkan sebuah produk. Dimana menulis memerlukan daya pikir yang kreativitas, konsentrasi, dan penuh dengan kebulatan hati. Menulis apapun itu dan menggunakan bahasa apapun itu menuntut daya kreatif seseorang agar tulisannya semakin bagus dan dapat dipahami oleh si pembaca. Namun dalam menulis dengan menggunakan bahasa asing (bahasa Inggris) siswa banyak mengalami kesalahan dalam menulis, secara umum kesulitan pembelajaran dalam menulis diantaranya adalah kesalahan dalam 
peletakan tanda baca, penyusunan struktur kalimat, dan pemilihan kosakata yang tepat.

Pembelajaran kooperatif mencakup beberapa teknik pembelajaran yang menarik dan menyenangkan diantara kegiatan yang dilakukan adalah mencari pasangan, bertukar pasangan. Selanjutnya metode ini dapat digunakan untuk mengajar kemampuan bahasa Inggris termasuk menulis. Menurut Wandy Jolliffe (2007:58) pembelajaran kooperatif cocok digunakan untuk mengajar menulis. Hal ini karena prinsip pembelajaran kooperatif adalah siswa belajar bersama untuk meraih prestasi. Dalam pembelajaran dikelas metode ini tepat digunakan untuk mengajar menulis, karena ketika siswa mengerjakan tugas menulis dalam kelompok, kemampuan menulis akan lebih muda dicapai oleh siswa dimana dalam pembelajaran kooperatif siswa dapat mengatasi masalah menulis seperti pengembangan ide, kosa kata, tata bahasa secara bersama-sama dalam kelompok. Siswa juga dapat mendiskusikan topik yang akan ditulis, dan juga siswa dapat berbagi pengetahuan dalam kelompok belajar mereka, sehingga siswa dapat menulis dengan mudah. Sehingga teknik seperti ini akan berpengaruh terhadap motivasi siswa dalam mengikuti pembelajaran di kelas dan bersemangat utuk menyelesaikan semua tugas yang diberikan oleh guru.

Selain itu dalam KTSP Bahasa Inggris dipaparkan pula bahwa salah satu tujuan pengajaran Bahasa Inggris adalah agar siswa mampu berkomunikasi secara tertulis dengan menggunakan ragam bahasa tulis yang sesuai secara lancar dan akurat dalam teks transaksional dan interpersonal serta esai pendek berbentuk narrative, recount, descriptive, report, dan procedure untuk beriteraksi dengan lingkungan.

Keterampilan menulis teks recount adalah menjadi fokus kajian peneliti dalam penelitian ini. Karena recount teks adalah bentuk tulisan yang tujuannya adalah membangun sebuah teks yang terorganisasi atau terstruktur yang dirangkai untuk menceritakan kejadian- kejadian pada masa lalu. Dengan kata lain, siswa menceritakan kejadian yang dialami kepada orang lain yang dapat diungkapkan melalui bentuk tulisan yang di dalamnya dituliskan kronologis peristiwa-peristiwa yang terjadi. Berdasarakan hasil observasi dan wawancara peneliti dengan salah satu guru bahasa Inggris di SMP Negeri 2 kelas VIII Way Tenong Lampung Barat pada tanggal 08 Oktober 2015, dengan Ibu Risda Yanti, S.Pd, beliau mengatakan bahwa ada beberapa kesulitan yang dialami siswa dalam menulis teks recount, yaitu pertama siswa kelas VIII sulit dalam membedakan penggunaan tenses yang tepat. Karangan yang seharusnya ditulis dalam bentuk past tense ditulis dalam bentuk present. Kedua, siswa kesulitan dalam mengurutkan rangkaian peristiwa secara tepat. Ketiga, selain masalah dalam struktur bahasa ternyata siswa di kelas VIII tersebut tidak begitu berminat dalam mengikuti pelajaran menulis. Bisa saja hal ini karena pengaruh ketidak pahaman siswa dalam konsep menulis tersebut. Keempat, metode yang dipakai oleh guru masih sangat sederhana atau bisa juga ketidakcocokan dalam memilih metode, misalnya dalam pembelajaran menulis guru menggunakan metode ceramah, sehingga hal ini menimbulkan kebosanan dan ketidakpahaman dari siswa tujuan dari pembelajaran tersebut.

Adapun tujuan yang ingin dicapai dalam penelitian ini adalah sebagai berikut: (1) Perbedaan keterampilan menulis teks Recount bahasa Inggris pada siswa yang belajar melalui teknik pembelajaran CIRC lebih tinggi daripada keterampilan menulis teks Recount pada siswa yang belajar melalui teknik pembelajaran STAD, (2) Pengaruh interaksi antara teknik pembelajaran kooperatif dan kecerdasan linguistik terhadap keterampilan menulis teks Recount bahasa Inggris, (3) Perbedaan keterampilan menulis teks recount bahasa Inggris siswa yang belajar dengan teknik pembelajaran CIRC lebih tinggi atau lebih baik daripada pada siswa yang belajar dengan teknik pembelajaran STAD pada kelompok siswa yang memiliki kecerdasan linguistik tinggi dan (4) Perbedaan keterampilan menulis teks recount bahasa Inggris siswa siswa yang belajar dengan teknik pembelajaran $C I R C$ lebih tinggi atau lebih baik daripada pada siswa yang belajar dengan teknik pembelajaran $S T A D$ pada kelompok siswa yang memiliki kecerdasan linguistik rendah.

Artikel ini bertujuan untuk mengkaji secara mendalam mengenai penerapan teknik pembelajaran dalam meningkatkan keterampilan menulis teks recount bahasa Inggris siswa. Keterampilan Menulis teks recount yang diukur dalam penelitian ini berdasarkan 5 aspek menurut J. Charles Alderson and Lyle F Bachman (2002:114-115) yaitu Isi, organisasi, kosa kata, tata bahasa, dan mekanika.

\section{KAJIAN LITERATUR}

\section{Hakikat Keterampilan Menulis teks recount Bahasa Inggris.}

\section{a. Pengertian Keterampilan Menulis}

Keterampilan menulis merupakan suatu kegiatan menyusun kalimat-kalimat yang benar sesuai dengan kaidah-kaidah gramatika. Keterampilan menulis tidak hanya sekadar menyusun kalimat sesuai dengan kaidah-kaidah gramatika dan penulisannya, tetapi juga memerlukan kegiatan untuk memahami dan 
merenungkan tulisan yang dapat dipahami oleh pembaca.

Menulis merupakan salah satu dari empat aspek keterampilan berbahasa. Dorn berpendapat bahwa menulis adalah sebuah proses komunikasi yang dipresentasikan melalui simbol-simbol makna dengan tujuan agar pesan yang dapat dikomunikasikan kepada orang lain. Menurut Rivers menulis sebenarnya mengkomunikasikan sebuah pesan yang dibatasi oleh waktu dan tempat. Rivers juga berpendapat bahwa menulis adalah sebuah seni yang membutuhkan usaha langsung secara sadar dalam pemilihan pola-pola bahasa.

Dari kedua pendapat tersebut sama-sama mengacu pada menulis sebagai proses melambangkan bunyibunyi ujaran berdasarkan aturan-aturan tertentu. Artinya, segala ide, pikiran dan gagasan yang ada pada penulis disampaikan dengan cara menggunakan lambang-lambang bahasa yang terpola. Melalui lambang-lambang tersebutlah pembaca dapat memahami apa yang dikomunikasikan oleh penulis.

\section{b. Menulis Teks Recount}

Kurikulum Tingkat satuan Pendidikan (KTSP) bahasa Inggris dipaparkan pula bahwa salah satu tujuan pengajaran bahasa Inggris adalah agar siswa mampu berkomunikasi secara tertulis dengan menggunakan ragam bahasa tulis yang sesuai secara lancar dan akurat dalam teks transaksional dan interpersonal serta esai pendek berbentuk naratif, recount, descriptif, report, dan prosedur untuk berinteraksi dengan lingkungan. Dalam hal ini peneliti mengambil teks recount sebagai salah satu variabel dari penelitian ini. Berikut penjelasan mengenai teks recount.

Menulis recount text siswa dituntut untuk membangun sebuah teks yang terorganisasi atau terstruktur yang dirangkai untuk menceritakan kejadian-kejadian pada masa lalu. Dengan kata lain, siswa menceritakan kejadian yang dialami kepada orang lain yang dapat diungkapkan melalui bentuk tulisan yang di dalamnya dituliskan kronologis peristiwa-peristiwa yang terjadi. Recount text adalah jenis teks yang berisi tentang pengalaman pribadi seseorang yang disampaikan secara terurut. Dari penjelasan tersebut recount text adalah siswa menceritakan suatu kejadian atau pengalaman yang pernah mereka alami.

Menurut Middle Primary, teks recount bertujuan untuk memberikan gambaran kepada pembaca tentang sebuah peristiwa yang terjadi menurut waktu dan tempat kejadiannya yang difokuskan adalah kejadian yang ditulis secara berurutan. Terdapat tiga jenis recount text, yaitu (1) personal recount: menceritakan kembali pengalaman di mana penulis telah terlibat secara langsung; (2) factual recount: menceritakan kembali kejadian atau insiden seperti berita koran, laporan kecelakaan, dan (3) imaginative recount: menceritakan peran yang bersifat imajinatif dan menghubungkan kejadian khayalan. Menulis teks recount adalah menceritakan suatu kejadian atau peristiwa yang sudah lampau, dan tujuan dari teks recount adalah menghibur pembaca atau menginformasikan pembaca. Kemudian teks recount juga terdapat beberapa jenis yang hendak diceritakan kepada pembaca.

Dimana sudah dijelaskan di atas bahwa teks recount adalah salah satu dari jenis teks bahasa Inggris yang menceritakan kembali kejadian-kejadian atau pengalaman-pengalaman di masa lampau. Tujuan dari teks recount adalah untuk memberikan informasi atau untuk menghibur pembaca.

\section{Tabel 1. Generic /Schematics Structure of} Recount Text ${ }^{1}$

\section{Generic structure/schema tic structure \\ Function}

\begin{tabular}{ll}
\hline $\begin{array}{l}\text { Orientation } \\
\text { Sequence of } \\
\text { events }\end{array}$ & $\begin{array}{l}\text { Pembukaan } \\
\text { tokoh, tempat, waktu dan } \\
\text { kejadian/aktivitas si pelaku }\end{array}$ \\
\hline $\begin{array}{l}\text { Re- } \\
\text { Orientation/Conc } \\
\text { lusion }\end{array}$ & $\begin{array}{l}\text { Sejadian yang dilakukan) } \\
\text { menjelaskan (penutup yang } \\
\text { perasaan si pelaku dengan } \\
\text { kejadian atau aktivitas } \\
\text { yang dilakukan. }\end{array}$ \\
\end{tabular}

\section{c. Penilaian Keterampilan Menulis Teks Recount.}

Rubrik penilaian menulis yang diadaptasi dari skala rubrik analitik untuk penilaian tes menulis menurut Alderson, yaitu menggunakan rubrik penilaian terdiri atas lima kriteria penilaian yang berbeda. Kriteria tersebut adalah (1) isi, (2) organisasi, (3) kosakata, (4) tata bahasa, dan (5) mekanika. Kelima criteria penulisan tersebut dijabarkan kedalam tabel rubrik penilaian recount text berikut ini.

Tabel 2. Kriteria Penilaian Keterampilan Menulis Teks Recount

\begin{tabular}{ccccc}
\hline No. & Ko & Sub komponen & Sk & Skor \\
& mp & indikator & or & Minimu \\
one & penilaian & ma & m \\
\hline
\end{tabular}

${ }^{1} \mathrm{lbid}$, h.107. 


\begin{tabular}{|c|c|c|c|c|}
\hline \multicolumn{2}{|r|}{ n } & & $\begin{array}{c}\text { ksi } \\
\text { ma } \\
\text { l }\end{array}$ & \\
\hline 1. & Isi & $\begin{array}{l}\text {-Wawasan } \\
\text { tentang isi } \\
\text {-Pengetahuan } \\
\text { topik } \\
\text { - Pengembangan } \\
\text { tesis } \\
\text {-Relevansi } \\
\text { dengan topik }\end{array}$ & 30 & 13 \\
\hline 2. & $\begin{array}{l}\text { Org } \\
\text { anis } \\
\text { asi }\end{array}$ & $\begin{array}{l}\text {-Kelancaran } \\
\text { pengungkapan } \\
\text {-Pengungkapan } \\
\text { gagasan } \\
\text { - } \\
\text { Pengorganisasia } \\
\text { n } \\
\text {-Urutan logis } \\
\text {-Kepaduan } \\
\text { kohesif }\end{array}$ & 20 & 7 \\
\hline 3. & $\begin{array}{l}\text { Kos } \\
\text { akat } \\
\text { a }\end{array}$ & $\begin{array}{l}\text { - } \\
\text { Perbendaharaan } \\
\text { kosakata } \\
\text { - pemilihan dan } \\
\text { penggunaan } \\
\text { Kosakata } \\
\text { - Penguasaan } \\
\text { bentuk kata } \\
\text { - Pemilihan } \\
\text { register }\end{array}$ & 20 & 7 \\
\hline 4. & $\begin{array}{l}\text { Tata } \\
\text { baha } \\
\text { sa }\end{array}$ & $\begin{array}{l}\text { - Konstruksi } \\
\text { kalimat } \\
\text { Kompleks dan } \\
\text { efektif } \\
\text { - Penggunaan } \\
\text { bentuk kata, } \\
\text { Kata sandang, } \\
\text { kata ganti } \\
\text { Dan kata depan }\end{array}$ & 25 & 5 \\
\hline 5. & $\begin{array}{l}\text { Mek } \\
\text { anik }\end{array}$ & $\begin{array}{l}\text { - Penggunaan } \\
\text { tanda baca } \\
\text { - Penggunaan } \\
\text { ejaan, tanda } \\
\text { Baca, dan huruf } \\
\text { capital }\end{array}$ & 5 & 2 \\
\hline & & & $\begin{array}{l}10 \\
0\end{array}$ & \\
\hline
\end{tabular}

\section{Hakikat Pembelajaran Kooperatif (Cooperative Learning)}

Pembelajaran kooperatif merupakan salah satu metode pembelajaran dimana para siswa bekerja dalam kelompok-kelompok kecil untuk saling membantu antara satu dengan yang lainnya dalam mempelajari materi. Dalam pembelajaran kooperatif di kelas, para siswa diharapkan dapat saling membantu, saling mendiskusikan, dan berargumentasi, untuk mengasah pengetahuan yang mereka kuasai saat itu dan menutup kesenjangan dalam pemahaman masing-masing. Metode pembalajaran kooperatif dapat digunakan secara efektif pada setiap tingkatan kelas dan untuk mengajarkan berbagai macam materi pembelajaran. Pembelajaran kooperatif juga dapat digunakan sebagai cara utama dalam mengatur kelas untuk pengajaran.

Selanjutnya metode ini dapat digunakan untuk mengajar kemampuan bahasa inggris termasuk menulis. Seperti menurut Wandy Jolliffe cooperative learning cocok digunakan untuk mengajar menulis. Hal ini karena prinsip cooperative learning adalah siswa belajar bersama untuk meraih prestasi. Dalam pembelajaran di kelas metode ini tepat digunakan untuk mengajar menulis, karena ketika siswa mengerjakan tugas menulis dalam kelompok, kemampuan menulis akan lebih muda dicapai oleh siswa dimana dalam pembelajaran kooperatif learning siswa dapat mengatasi masalah menulis seperti pengembangan ide, kosa kata, tata bahasa secara bersama-sama dalam kelompok. Siswa juga dapat mendiskusikan topik yang akan ditulis, dan juga siswa dapat berbagi pengetahuan dalam kelompok belajar mereka, sehingga siswa dapat menulis dengan mudah.

\section{3. kecerdasan linguistik.}

Salah satu teori mengenai kecerdasan adalah teori Primary Mental Ability yang dikembangkan oleh L.L Thustone. Teori ini menjelaskan bahwa kecerdasan atau intelegensi tidak terdiri dari dua atau multifactor, akan tetapi terdiri dari sejumlah kecakapan-kecakapan mental yang primer.

Ada beberapa factor primer dalam kecerdasan yaitu: Verbal Comprehension (kemampuan verbal) yang merupakan kemampuan menggunkan bahasa, Word Fluency (kefasihan kata-kata), yaitu faktor kelancaran atau kefasihan menggunakan kata, dan faktor ini secara umum dianggap sesuatu indikator mudah tidaknya seseorang mengubah rasionya dan mengalihkan rasionya sesuai kebutuhan, Number Facility (faktor bilangan) yaitu kemampuan untuk bekerja dengan bilangan (kecakapan hitung menghitung). Spatial relation (relasi ruang) merupakan suatu kemampuan untuk mengadakan orientasi dalam ruang (baik dua atau tiga dimensi). Associative memory atau faktor ingatan, yaitu merupakan kemampuan untuk mengingat. Perceptual Speed (kecepatan persepsi) yaitu faktor persepsi merupakan suatu kemampuan untuk 
mengamati dengan cermat dan tepat. Induction (induksi), yaitu kemampuan untuk berpikir yang logis. Thurstone lebih lanjut menjelaskan bahwa pengukuran verbal comprehension atau pemahaman verbal, analogi verbal, kalimat yang diacak, penalaran verbal, dan pencocokan kata.

\section{METODE PENELITIAN}

Penelitian ini merupakan penelitian dengan desain eksperimen sesuai rancangan desain faktorial $2 \times 2$. Teknik analisis data yang digunakan adalah analisis varian (ANAVA) dua jalur pada tahaf signifikan $\alpha=$ 0,05 dan $\alpha=0,01$ apabila di dalam analisis ditemukan adanya interaksi, maka dilanjutkan dengan uji tuckey. Sebelum dilakukan uji hipotesis terlebih dahulu dilakukan uji persyaratan yang meliputi uji normalitas dan uji homogenitas. Uji normalitas yang dilakukan menggunakan uji liliefort, sedangkan uji homogenitas menggunakan uji Bartlett.

\section{HASIL DAN PEMBAHASAN}

\section{Uji Normalitas Data}

Pengujian normalitas data dalam penelitian ini dilakukan terhadap empat kelompok data, yaitu $\mathrm{A}_{1} \mathrm{~B}_{1}$ (skor hasil keterampilan menulis teks recount siswa yang belajar menggunakan teknik pembelajaran (CIRC) untuk kelompok siswa yang memiliki kecerdasan linguistik tinggi), (skor hasil keterampilan menulis teks recount siswa yang belajar menggunakan teknik pembelajaran (CIRC) untuk kelompok siswa yang memiliki kecerdasan linguistik rendah, $\mathrm{A}_{2} \mathrm{~B}_{1}$ (skor hasil keterampilan menulis teks recount siswa yang belajar dengan teknik pembelajaran (STAD) untuk kelompok siswa yang memiliki kecerdasan linguistik tinggi, $\mathrm{A}_{2} \mathrm{~B}_{2}$ ( skor hasil keterampilan menulis teks recount siswa yang belajar menggunakan teknik pembelajaran $(S T A D)$ untuk kelompok siswa yang memiliki kecerdasan linguistik rendah).

\section{Uji Homogenitas}

Pengujian homogenitas varians dilakukan terhadap empat kelompok data. Keempat kelompok data tersebut harus memenuhi asumsi bahwa variansinya homogen agar dapat dilakukan pengujian terhadap skor rata - rata antar kelompok perlakuan. Hasil pengujian dengan uji Barlett pada $\mathrm{a}=0,05$ dan derajat dan derajat kebebasan $=3$ ditunjukkan pada tabel di berikut.

Tabel 3. Hasil Perhitungan Uji Homogenitas

\begin{tabular}{|c|c|c|c|c|}
\hline \multirow{3}{*}{$\begin{array}{l}\text { Kelompok } \\
\text { Data }\end{array}$} & \multirow{3}{*}{$\begin{array}{l}\mathbf{X}^{2} \\
\text { Hitung }\end{array}$} & \multicolumn{2}{|c|}{$\mathrm{X}^{2}$ Tabel } & \multirow{3}{*}{ Kesimpulan } \\
\hline & & & & \\
\hline & & $\begin{array}{l}\alpha= \\
0,01\end{array}$ & $\begin{array}{l}\alpha= \\
0,05\end{array}$ & \\
\hline $\begin{array}{l}\mathbf{A}_{1} \mathbf{B}_{1} \\
\mathbf{A}_{1} \mathbf{B}_{2} \\
\mathbf{A}_{2} \mathbf{B}_{1} \\
\mathbf{A}_{2} \mathbf{B}_{2}\end{array}$ & 2,03 & 21,66 & 16,9 & Homogen \\
\hline
\end{tabular}

Hasil pengujian mengindifikasikan bahwa $\mathrm{X}^{2}$ hitung lebih kecil dari nilai $\mathrm{X}^{2}$ tabel sehingga dapat disimpulkan bahwa keempat kelompok data yang diuji berasal dari sampel yang variansinya homogen.

Berdasarkan kedua hasil pengujian persyaratan analisis di atas dapat disimpulkan bahwa persyaratan yang diperlukan untuk analisis varians telah terpenuhi, sehingga layak untuk dilakukan analisis lebih lanjut untuk melihat perbedaan pengaruh teknik pembelajaran berdasarkan tingkat kecerdasan linguistik terhadap hasil keterampilan menulis teks recount siswa pada kelompok perlakuan.

Pengujian Hipotesis dan Pembahasan

Untuk menguji hipotesis, terlebih dahulu dilakukan analisis varians dua jalur dengan interaksi (ANAVA 2X2). Tujuan analisis ini untuk melihat perbedaan pengaruh perlakuan yakni teknik pembelajaran kooperatif (teknik pembelajaran CIRC dan teknik pembelajaran STAD) serta kecerdasan linguistik terhadap hasil keterampilan menulis teks recount siswa. Dapat dilihat dari table berikut:

ANAVA Dua Jalur untuk Melihat Pengaruh Teknik Pembelajaran dan Kecerdasan Linguistik terhadap Hasil Keterampilan Menulis teks Recount. 
Tabel 4. Anava Dua Jalur

\begin{tabular}{|c|c|c|c|c|c|c|}
\hline Sumber & $\mathrm{D}$ & Jumlah & Mean & $\mathrm{Fh}$ & Ftabel & \\
\hline Varians & $\mathrm{k}$ & Kuadrat & Kuadrat & & $(5 \%)$ & $(1 \%)$ \\
\hline & & & & & 1,44 & 1,44 \\
\hline Antar Kolom (K) & 1 & 55,225 & 55,225 & 0,9 & 0,25 & 0,294 \\
\hline & & & & 9 & 8 & \\
\hline Antar Baris (B) & 1 & 98,775 & 98,775 & 1,7 & 0,25 & 0,294 \\
\hline & & & & 7 & 8 & \\
\hline Interaksi (I) & 1 & 142,075 & 142,075 & 2,5 & 0,25 & 0,294 \\
\hline & & & & 4 & & \\
\hline Dalam (D) & 4 & 2006,7 & 5,57 & & & \\
\hline & 0 & & & & & \\
\hline Total & 4 & & & & & \\
\hline & 3 & & & & & \\
\hline
\end{tabular}

Hasil uji perbandingan menggambarkan bahwa hasil keterampilan menulis teks recount yang belajar menggunakan teknik pembelajaran (CIRC) lebih baik daripada hasil keterampilan menulis teks recount siswa yang belajar menggunakan teknik pembelajaran $(S T A D)$.

Pengujian hipotesis pertama menunjukkan bahwa terdapat perbedaan yang signifikan antara teknik pembelajaran $(C I R C)$ dan teknik pembelajaran $(S T A D)$, teknik pembelajaran $(C I R C)$ memberikan pengaruh yang cukup baik bila dibandingkan dengan teknik pembelajaran $(S T A D)$ terhadap hasil keterampilan menulis teks recount siswa.

Pada hipotesis kedua, berdasarkan perhitungan ANAVA dapat dilihat bahwaaa $F_{\text {htung }}$ untuk faktor interaksi adalah 25, 50 lebih besar daripada $\mathrm{F}_{\text {tabel }}=$ 2, 95 untuk $\alpha=0,05$ dan $\mathrm{F}_{\mathrm{t}}=4,02$ untuk $\alpha=0,01$. Karena $\mathrm{Q}_{\text {hitung }}=13,09>\mathrm{Q}_{\text {tabel }}=3,15$ pada taraf nyata $\alpha=0,05$ dan pada taraf nyata $\alpha=0,01$ diperoleh $\mathrm{Q}_{\text {tabel }}=4,48$, maka dapat disimpulkan bahwa terdapat pengaruh interaksi yang sangat signifikan antara teknik pembelajaran kooperatif dan kecerdasan linguistik (tingi dan rendah) terhadap hasil keterampilan menulis teks recount siswa.

Pada hipotesis ketiga, Karena $\mathrm{Q}_{\text {hitung }}=7,45>\mathrm{Q}_{\text {tabel }}$ $=3,15$ pada taraf nyata $\alpha=0,05$ dan pada taraf nyata $\alpha=0,01$ diperoleh $\mathrm{Q}_{\text {tabel }}=4,48$. Berdasarkan hasil analisis varians dan uji pembanding, uji Tuckey tersebut dapat disimpulkan bahwa untuk siswa yang memiliki kecerdasan linguistik tinggi, hasil keterampilan menulis teks recount siswa lebih baik yang menggunakan teknik pembelajaran $(S T A D)$ daripada kelompok dengan teknik pembelajaran $(C I R C)$.

Pada hipotesis keempat, Karena $Q_{\text {hitung }}=10,18>$ $\mathrm{Q}_{\text {tabel }}=3,15$ pada taraf nyata $\alpha=0,05$ dan pada taraf nyata $\alpha=0,01$ diperoleh $\mathrm{Q}_{\text {tabel }}=4,48$. Berdasarkan hasil analisis varians dan uji pembanding, uji
Tuckey terhadap dua kelompok tersebut dapat disimpulkan bahwa hasil keterampilan menulis teks recount siswa untuk kelompok yang memiliki kecerdasan linguistik rendah, lebih baik belajar menggunakan teknik pembelajaran (CIRC) daripada belajar menggunakan teknik pembelajaran (STAD).

\section{KESIMPULAN}

Berdasarkan hasii pengujian hipotesis, penelitian ini membuktikan bahwa secara keseluruhan, berdasarkan skor menulis teks Recount, keterampilan menulis teks recount pada kelompok siswa yang belajar menggunakan teknik pembelajaran (CIRC) lebih baik daripada siswa yang belajar menggunakan teknik pembelajaran (STAD).

1. Adanya pengaruh interaksi antara teknik pembelajaran dan kecerdasan linguistik terhadap keterampilan menulis teks recount siswa.

2. Kelompok siswa dengan kecerdasan linguistik tinggi, penerapan dengan teknik pembelajaran (CIRC) memberi hasil keterampilan menulis teks recount yang lebih baik dibandingkan dengan penerapan penggunaan teknik pembelajaran (STAD).

3. Kelompok siswa yang memiliki kecerdasan linguistik rendah, keterampilan menulis teks recount siswa lebih baik jika belajar menggunakan teknik pembelajaran (STAD) dibandingkan menggunakan teknik pembelajaran (CIRC).

\section{PROFIL PENULIS}

Oktariyani, lahir pada tanggal 14 Oktober 1988 di Banjit, Lampung Utara, sebagai anak kedua dari 
pasangan bapak alm. Tapsilo dan ibu Maisarah. Istri dari Ahmad Qosasih ini pernah bersekolah di SD N 1 Banjit pada tahun 1994, lalu pada tahun 1997 pindah ke SDN 1 M. Emil dan lulus SD pada tahun 2000. Masuk SMP Negeri 02 Tanjung Agung dan lulus pada tahun 2005, lalu masuk SMA di Baturaja yaitu di SMA Muhammadiyah, dan lulus pada tahun 2007. Kemudian kuliyah SI di Universitas Baturaja mengambil jurusan Pendidikan Bahasa Inggris, dan lulus pada tahun 2011. Tahun 20012 masuk Program S2 Pendidikan Bahasa PPS Universitas Negeri Jakarta (UNJ). Lulus pada tahun 2014.

Oktariyani pernah mengajar di lembaga kursus NEC (National English Centre) Utan Kayu Jakarta Timur. Pernah mengajar di SD Perguruan Rakyat 3 Jakarta sebagai guru eskul Bahasa Inggris. Mengajar juga di yayasan Islam Al-hidayah Pondok Bambu. Pernah mengajar di British Education Pondok Gede Bekasi. Saat ini Oktariyani adalah dosen tetap di Universitas Nahdlatul Ulama Lampung. Dan dosen luar biasa di di Universitas Trilogi Jakarta.

Laini Asra, lahir di Sukananti, 23 Januari 1987. Pernah bersekolah di SD N 1 Sukaraja. lulus SD pada tahun 1996. Masuk SMP Negeri 01 Way Tenung. lulus pada tahun 2002. Sekolah di MAN 2 Tanjung Karang lulus pada tahun 2005. Menyeselaikan kuliah diploma III di Universitas Lampung jurusan Pendidikan Bahasa Inggris. Lulus pada tahun 2009. dan melanjutkan S1 di STKIP Bandar Lampung mengambil jurusan Pendidikan Bahasa Inggris.. Tahun 20011. Masuk Program S2 Pendidikan Bahasa PPS Universitas Negeri Jakarta (UNJ). Lulus pada tahun 2014. Laini Asra pernah mengajar di SMA N 1 Bandar Negeri Ruoh Lampung Barat, 2010-2011. dan saat ini megajar di SMP N 1 Sumber Jaya Lampung Barat.

\section{DAFTAR PUSTAKA}

Alderson, JCharles \& Lyle F Bachman. (2002) Assessing Writing. Cambridge: University Press.

Anita, Lie. (2010). Cooperative Learning. Jakarta: Gramedia.

Agus, Suprriojono. (2012). Cooperative

Learning Teori dan Aplikasi Paikem .Yogyakarta: Pustaka.

Burhan, Nurgiyantoro. (2010).
Penilaian Pembelajaran Bahasa Berbasis Kompetensi. Yogyakarta: BPFE Yogyakarta.

Connelly, Mark. (2013) The Sundance Writer: A Rhetoric, Reader, Research Guide, and Handbook USA: Publication.

Daeng Nurjamal, Warta Sumirat; Riadi

Darwis. (2011) Terampilan Berbahasa, Menyusun Karya Tulis Akademik, Memandu Acara (MC-Moderator), dan Menulis Surat . Bandung: Penerbit Alfabeta.

Elizabeth G. Cohen. (2004). Teaching Cooperative Learning. New York:University State.

H. Douglas Brown. (2004). Language

Assessment: Principles and Classroom Practices. White Plains NY: Pearson Education.

Isjoni. (2010). Cooperative Learning

Efektifitas Pembelajaran Kelompok. Bandung: Alfabeta.

Jolliffe, Wandy. (2007) Cooperative Learning in The Classroom. London: Publication Company.

Judy S, Richardson, Raymond F. Morgan, and Charlene Fleener. (2009). Reading to Learn in the

Content Area. USA.

.JB. Heaton. (1988) Writing English

Language Tests. London: Longman Handbooks for Language Teachers.

Jack C. Richards, Willy a. Renandya.

(2002) Methodology in Language Teaching, An Anthology of Current Practice Australia: Cambridge University Press.

J. Charles Alderson \& Lyle F Bachman.

(2002). Assesing $\quad$ Writing.
Cambridge:University Press.

Jeremy, Harmmer. (2004). How to

Teach Writing. England: Pearson Educational Limited. 
Mark, Connelly, The Sundance Writer.

(2013) A Rhetoric, Reader, Research Guide, and Handbook

USA:Publication.

Regina, L Smalle, Mary K Ruentte; and

Joann Rishel Koz. (2007). Developing Writing Skills. Singapore: Learners Publishing Pte Ltd.

Slavin, Robert E. (2005) Cooperative Learning; Teori, Riset, dan Praktik. London: Allemand Bacon.

Sabarti, Akhadiah, Maidar G. Arsjad

dan Sakura H. Ridwan. (2003) Pembinaan Kemampuan Menulis Bahasa Indonesia Jakarta: Erlangga.

Sharon Vaughn dan Candaces Bos.

(2009). Strategis for Teaching Students with Learning and

Behavior Problems. Austin: University of Texas.

Spencer, kagan \& Miguel Kagaan.

(2009). Kagan Cooperative Learning (Kagan Publishing.

Vicki, Urquhart dan Monette McIver.

(2005). Teaching Writing in the Content Areas. USA: ASCD Publication.

Wandy, Jolliffe. (2007). Cooperative

Learning in The Classroom. London: Publication Company. 